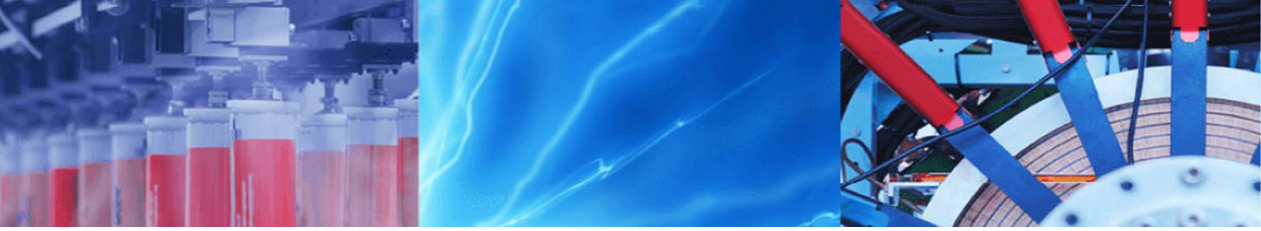

Research Article

\title{
Techno-economic and environmental design of an optimal hybrid energy system for a community multimedia centre in Cameroon
}

\author{
Franck Armel Talla Konchou ${ }^{1,2}$ D $\cdot$ Hermann Djeudjo Temene ${ }^{1} \cdot$ René Tchinda $^{2} \cdot$ Donatien Njomo $^{1}$
}

Received: 12 June 2020 / Accepted: 4 January 2021 / Published online: 12 January 2021

(C) The Author(s) 2021 OPEN

\begin{abstract}
Hybrid Renewable Energy System is a very good solution to the energy deficit encounter in developing countries. The paper presents the optimal design of a hybrid renewable energy system regarding the technical aspect that is Loss of Power Supply Probability (LPSP), economic aspect that is Cost of Electricity (COE) and Net Present Cost (NPC) and environmental aspect that is Total Greenhouse gases emission (TGE) aspects using a multi-objective Particle Swarm Optimization algorithm for a Community multimedia center in MAKENENE, Cameroon. Optimal configurations including Photovoltaic (PV), Wind, Battery and Diesel generator (DG), separated into Scenarios 1-7 of hybrid energy systems are tested to have the most appropriate Scenario. Scenario 3 (Hybrid system with PV, Battery and DG) with Loss of Power Supply Probability, Cost of Electricity, Net Present Cost and Emission of $0.003 \%, 0.132 \$ / \mathrm{kWh}, 38,817.7 \$$ and $2.2 \mathrm{~kg} / \mathrm{year}$ respectively is found to be the most appropriate for the Community multimedia center.
\end{abstract}

Keywords Hybrid renewable energy system · Particle swarm optimization · Loss of power supply probability · Cost of electricity $\cdot$ Net present cost $\cdot$ Emission of greenhouse gases

\section{Introduction}

In a rapidly changing world, marked by an increase in the population notably in developing countries and the development of digital and communication technologies, the demand for electricity is also fast increasing. For the reason, the access to a cheap, clean and reliable electricity has become a major concern worldwide. Therefore, the necessity to integrate renewable energy sources in the production of such electricity must not be underestimated [1]. Solar and wind energy have an intermittent nature because they both depend on weather conditions. Hence the design of a Hybrid Renewable Energy System (HRES) is indispensable. For the past decades, many scientists have been working on such a system using a Diesel generator as a back-up especially for the case of an off-grid HRES; trying to look for an optimal configuration that will at the same time be economical, reliable and environmentally less harmful. Many benchmarked and commercial software packages such as HOMER, RETScreen, Hybrid2, TRNSYS, RAPSIM, and INSEL have been developed and are successfully used in the optimal sizing of HRES. The Hybrid Optimization Model for Electric Renewable (HOMER), developed by the National Renewable Energy Laboratory has proven to be one of the most important among the software [2]. The authors in [3] used it to simulate and achieve an optimal renewable system configuration of Photovoltaic (PV)Wind turbine (WT)-Battery which is reliable and economical. The authors in [4] also used it to optimally design a standalone hybrid energy system containing a Biomass generator set, Fuel cell and PV with battery storage system to entirely meet the power demand of an energy center

$\triangle$ Franck Armel Talla Konchou, tkfarmel@yahoo.fr | ${ }^{1}$ Environmental Energy Technologies Laboratory (EETL), Department of Physics, University of Yaounde I, P.O Box 812, Yaounde, Cameroon. ${ }^{2}$ URISIE, University Institute of Technology Fotso Victor, University of Dschang, P.O Box 134, Bandjoun, Cameroon. 
in MANIT Bhopal (India). In [6], the authors used HOMER to successfully design a system with a high penetration of renewable energy sources in order to replace the existing diesel generator in some facilities in the Northern region of Cameroon. The authors in [5] used HOMER to carry out the techno-economic feasibility analysis of an off-grid hybrid energy system for the electrification of a secondary school in the rural area of Nigeria.

Another approach to solve a HRES optimization problem consist of using heuristic algorithms based on artificial intelligence and this have proven to be powerful optimization tools in resolving complex optimization problems. Some of these algorithm include Genetic Algorithm (GA), Evolutionary Algorithm (EA), Particle Swarm Optimization (PSO), Cat Swarm Optimization (CSO), Simulated Annealing (SA), Imperialistic Comparative Algorithm (ICA), Biogeography Based Optimization (BBO), Teaching Learning Based Optimization (TLBO), and Grey Wolf Optimization (GWO). Among these, PSO, GWO and TLBO are recognized as very promising algorithms because they are simple to implement, have high efficiency and fast convergence [7]. The authors in [8] used PSO to minimize and compare the Net Present Cost (NPC) of a micro-grid system which was composed of PV, WT, diesel generator (DG) and battery in two towns of two different countries (Iraq and Morocco) using Loss of Power Supply Probability (LPSP) and Renewable Fraction as constraints. In order to optimize the Cost of Electricity (COE) of a standalone HRES composed of wind turbines, PV, tidal turbines and battery bank, the authors in [9] used PSO on various scenarios considering the State Of Charge (SOC) of the energy storage system, high reliability, and planning expansion for the future development as constraints and noticed an optimal solution at a time rate better than $80 \%$ of conventional technology and in less than 20 iterations. In the same way, the authors in [10] minimized the cost of a grid-connected hybrid system for residential application, incorporating a solar-wind-fuel cell combined heat and power system using PSO which they compared to GA in terms of accuracy and speed. PSO was equally used by the authors in [11] to investigate for minimum system cost and minimum pollution for a PV/ Battery bank/DG system for a typical house in Tunisia considering assumptions on the parameters of the PSO. The authors in [12] used PSO to optimize a Hybrid Micro-Grid System (HMGS) in three stations in Iran based on reliability and cost for a number of households. In [13], the authors optimized a hybrid renewable energy system consisting of wind turbines, solar cells, micro-hydro generator, diesel generator, battery bank, electrolyzer, hydrogen tanks and fuel cell using PSO considering NPC, COE as objective functions in order to meet equivalent loss factor (ELF) index.

A country like Cameroon whose aim is to become an emerging country by 2035 has to emphasize on the development of its telecommunication and energy sectors which are indispensable in the process of development of a country. The current electricity grid of Cameroon is divided into three main networks as follows [14]: the South Interconnected Network (SIN) covering six regions (Centre, Littoral, West, North-West, South-West and South), the North Interconnected Network (NIN) covering the northern part of the country (Adamawa, North and Far North) and the East Interconnected Network (EIN) for the East region only. Cameroon has a renewable energy potential which as follows [15]: hydroelectric which is estimated at about $115 \mathrm{GWh} /$ year (of which just $4 \%$ is exploited), solar potential of $4.5 \mathrm{kWh} / \mathrm{m}^{2} /$ day in the South and $5.74 \mathrm{kWh} /$ $\mathrm{m}^{2} /$ day in the North, biomass electric potential of about $1072 \mathrm{GWh}$ and wind potential of about 2-4 m/s of wind speed in the Far North region (KAELE end Lake Chad) and up to $6.6 \mathrm{~m} / \mathrm{s}$ on Mount BAMBOUTOS in the West region. With all this renewable energy potential, renewable energies occupy a very small portion in the energy mix of the country with barely $0.1 \%[16]$.

MAKENENE is a town located in the Centre region of Cameroon that is on the SIN with a density which gradually decreased from $66.1 \%$ in 1976 to $61.9 \%$ in 2012 [14]; thus making the town of MAKENENE to spend at times 3 to 4 days of blackout. This has a negative impact on the development of the town notably in the telecommunication sector given that the town hosts one the first Community Multimedia Centre constructed in 2006 to give access telecommunication facilities to the local population.

The objective of this study is to design and optimize a standalone HRES in order to have a reliable, cost effective and less polluting system to meet the power demand of the Community Multimedia Centre in MAKENENE. To achieve this, a multi-objective PSO optimization method is applied in order to find the LPSP, the lowest NPC, the COE and the lowest quantity of the Total Greenhouse gases emission (TGE).

The paper is organized in seven sections as follows: Sect. 1 on "Introduction", Sect. 2 on "Hybrid energy system modeling", Sect. 3 on "Power Management Strategy", Sect. 4 on "Optimization", Sect. 5 on "Particle Swarm Optimization algorithm", Sect. 6 on "Results and Discussion" and lastly Sect. 7 on "Conclusion".

\section{Hybrid energy system modeling}

\subsection{Modeling photovoltaic}

This consists of solar panels which can be connected in series, in parallel or both in series and parallel. The power output of the PV system is given by the Eq. (1) [12]: 
$P_{p v-\text { out }}=P_{p v-\text { rated }} \times\left(\frac{G}{G_{\text {ref }}}\right) \times\left[1+K_{T}\left(T_{c}-T_{\text {ref }}\right)\right]$

where $P_{p v-o u t}$ is the output power from the PV system, $P_{p v-\text { rated }}$ is the rated power at the reference conditions, $G$ is the solar radiation $\left(\mathrm{W} / \mathrm{m}^{2}\right), G_{\text {ref }}$ is the solar radiation at reference conditions $\left(\mathrm{G}_{\text {ref }}=1000 \mathrm{~W} / \mathrm{m}^{2}\right), T_{\text {ref }}$ is the cell temperature at reference conditions $\left(\mathrm{T}_{\text {ref }}=25^{\circ} \mathrm{C}\right), K_{T}$ is the temperature coefficient of the maximum power $\left(K_{T}=-3.7 \times 10^{-3} /{ }^{\circ} \mathrm{C}\right)$ and $T_{C}$ is the cell temperature which is determined by the Eq. (2)

$T_{c}=T_{a m b}+(0.0256 \times G)$

$T_{a m b}$ is the ambient temperature.

The input parameters for the PV are given in Table 1.

\subsection{Modeling wind turbine}

It is well-known that the wind speed varies with height, the measured wind speed can be converted to desired hub heights. The power equation is calculated by the following correlation [12]:

$\frac{v_{2}}{v_{1}}=\left(\frac{h_{2}}{h_{1}}\right)^{\alpha}$

where $v_{2}$ is the wind speed at the hub height $h_{2}(70 \mathrm{~m}$ in this work), $v_{1}$ is the wind speed at the reference height $h_{1}$ (10 $\mathrm{m}$ in this work) and $\mathrm{a}$ is the coefficient of friction (Hellman exponent, wind gradient or power-law exponent) with value equal to 0.25 for this work [17].

The power output of wind turbine can be calculated using Eq. (4) [5]:

$P_{\text {wind }}=N_{w} \begin{cases}0, & v \leq v_{c i}, v \geq v_{c o} \\ v^{3}\left(\frac{P_{r}}{v_{r}^{3}-v_{c i}^{3}}\right)-P_{r}\left(\frac{v_{c i}^{3}}{v_{r}^{3}-v_{c i}^{3}}\right), & v_{c i}<v<v_{r} \\ P_{r}, & v_{r}<v<v_{c o}\end{cases}$

where $N_{w}$ is the number of wind turbines, $P_{r}$ is the rated power of the turbine, $v$ is the hourly wind speed, $v_{c i} v_{r}$ and $v_{c o}$ represent the cut-in, rated and cut-out wind speed

Table 1 PV input parameters

\begin{tabular}{lc}
\hline PV initial cost & $1800 \$ / \mathrm{kW}$ \\
Annual operation and maintenance cost & $0.01{ }^{*}$ initial \\
& cost $\$ /$ \\
near & \\
Rated power & $260 \mathrm{~W}$ \\
PV nominal temperature & $45^{\circ} \mathrm{C}$ \\
efficiency & $90 \%$ \\
PV system lifetime & 20 years
\end{tabular}

respectively. The input parameters for the Wind turbine are given in Table 2.

\subsection{Battery modeling}

In the absence of the sun and the wind to supply the load, the battery bank used as a storage system may be needed to avoid the use of the diesel generator. The storage capacity depends on the state of charge (SOC) of the battery. The battery storage capacity $\left(C_{B}\right)$ is given by Eq. (5) [9]:

$C_{B}=\frac{\left(E_{L} \times A D\right)}{\eta_{\text {inv }} \times \eta_{\text {bat }} \times D O D}$

where $E_{L}$ is the daily average load energy, $A D$ is the number of days of autonomy, $\eta_{i n v}$ and $\eta_{b a t}$ represent the battery and the inverter efficiency respectively, and $D O D$ is the battery's depth of discharge. The input parameters for the Battery are given in Table 3.

\subsection{Diesel generator modeling}

The performance of the diesel generator is usually characterized by its efficiency, the fuel consumption and the type of fuel used. The fuel consumption is determined by Eq. (6) which is the linear model of a DG set hourly fuel consumption [8]:

$F_{d g}=B_{g} P_{d g}+A_{g} P_{d g-o u t}$

where $P_{d g-\text { out }}$ is the DG output power, $P_{d g}$ is the DG rated power, $A_{g}$ and $B_{g}$ are constants representing the coefficient of fuel consumption which approximately the values

Table 2 Wind turbine input parameters

\begin{tabular}{ll}
\hline Wind initial cost & 2000 \$/unit \\
Annual operation and maintenance cost & $0.01 *$ initial cost \$/year \\
Rated power & $1 \mathrm{~kW}$ \\
Cut-in wind speed & $2.5 \mathrm{~m} / \mathrm{s}$ \\
Rated wind speed, Cut-out wind speed & $10 \mathrm{~m} / \mathrm{s}, 25 \mathrm{~m} / \mathrm{s}$ \\
Wind system lifetime & 20 years \\
\hline
\end{tabular}

Table 3 Battery input parameters

Battery initial cost
Annual operation and maintenance cost
Depth of discharge
Battery efficiency
Minimum charge of the battery
Battery system lifetime

$280 \$ / \mathrm{kWh}$
$0.03 *$ initial
cost $\$ / \mathrm{kWh} /$
year
$80 \%$
$85 \%$
$20 \%$
10 years


Table 4 DG parameters

Diesel generator initial cost

Annual operation and maintenance cost

Rated power

Replacement cost

Fuel cost

Diesel generator lifetime
$1000 \$ / \mathrm{kW}$

$0.008 \$ / \mathrm{kWh}$

$4 \mathrm{~kW}$

$1000 \$ / \mathrm{kW}$

1 \$/liter

$25,000 \mathrm{~h}$

$0.246179 \mathrm{l} / \mathrm{kW}$ and $0.08415 \mathrm{l} / \mathrm{kW}$ respectively. The input parameters for the DG are given in Table 4.

\subsection{Load profile}

The Community Multimedia center of MAKENENE is located on Latitude: $4^{\circ} 52^{\prime} 36,3^{\prime \prime} \mathrm{N}$, Longitude: $10^{\circ} 48^{\prime} 49,6^{\prime \prime} \mathrm{E}$ and at an altitude of $700 \mathrm{~m}$. It is some $198 \mathrm{~km}$ away from YAOUNDE on the National Road Number 5. The multimedia center consists of electrical appliances such as desktop computers, printers, scanners, fixed phones, TV and light bulbs. Figure 1 shows how these electric load can be connected to power source. The daily energy load is approximately $50.22 \mathrm{kWh}$. The load profile for the multimedia

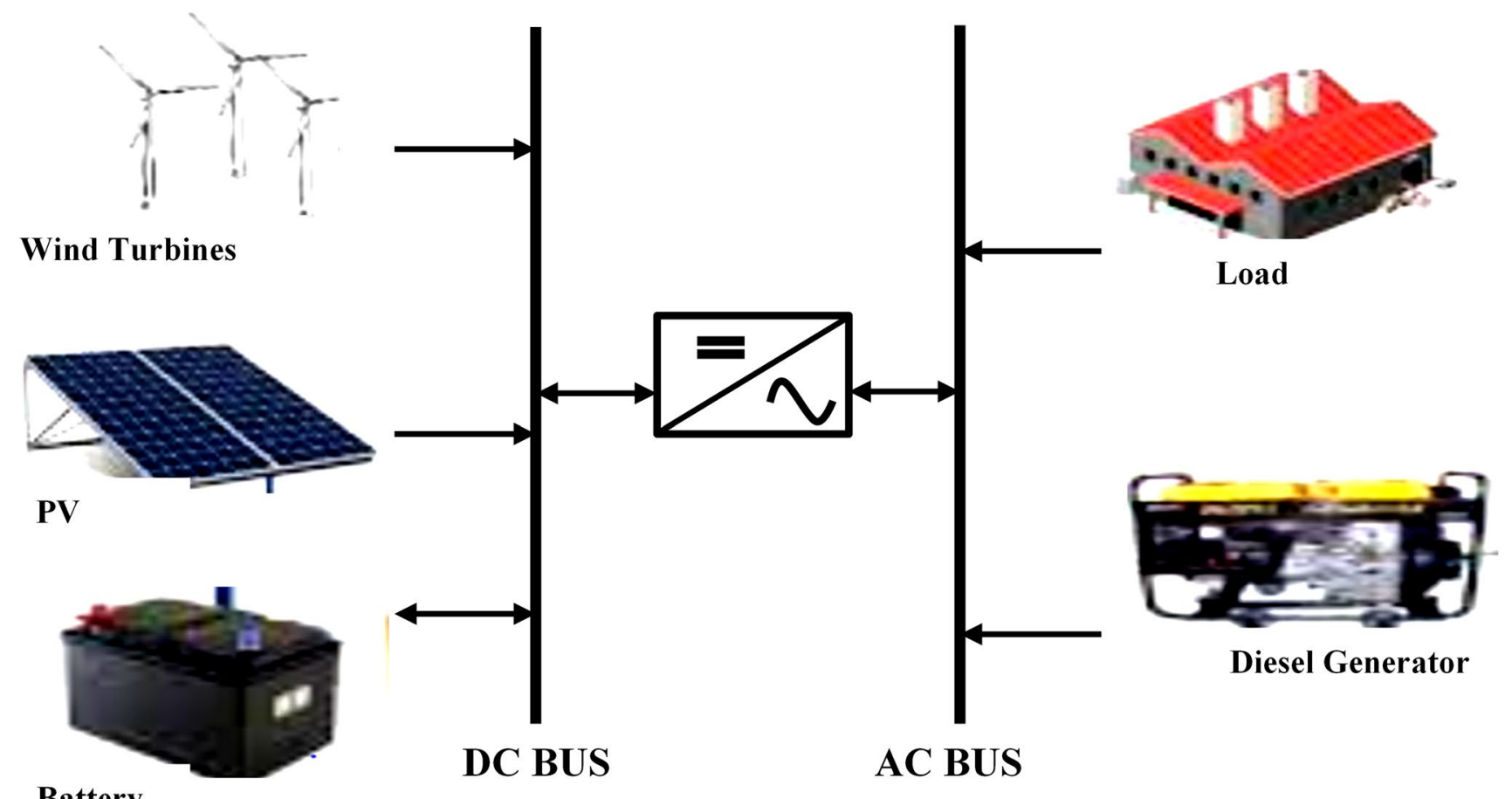

Battery

Fig. 1 Standalone hybrid renewable energy system

Fig. 2 Load profile

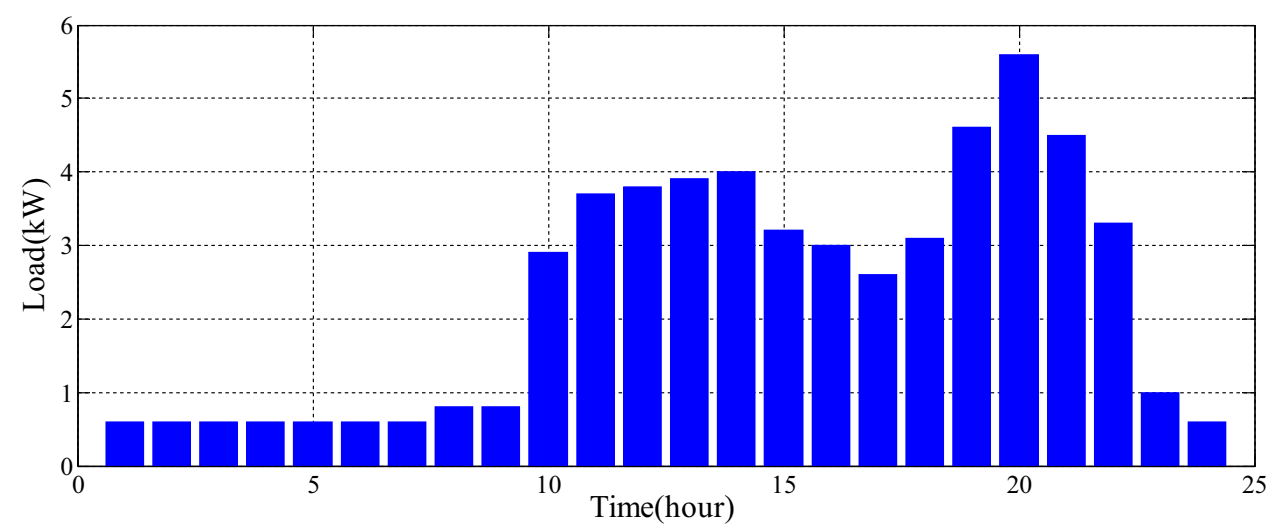


center is worked on hourly basis. Figure 2 shows this load profile; the average load is $2.32 \mathrm{~kW}$ and the peak load of the day is $5.6 \mathrm{~kW}$. The meteorological data for the site used in this study were obtained National Aeronautics and Space Administration (NASA) (2010).These are represented in Figs. 3, 4 and 5

Fig. 3 Hourly wind speed

Fig. 4 Hourly ambient temperature

Fig. 5 Hourly solar radiation

\section{Power management strategy}

The intermittent nature of renewable resources usually makes the power management strategy very complex. This strategy includes many scenarios which are briefly described below [18]:

- Case 1: The battery will charge when the load is satisfied by all renewable energies.

- Case 2: The load will be satisfied by the battery when renewable energies are not able to meet the load.
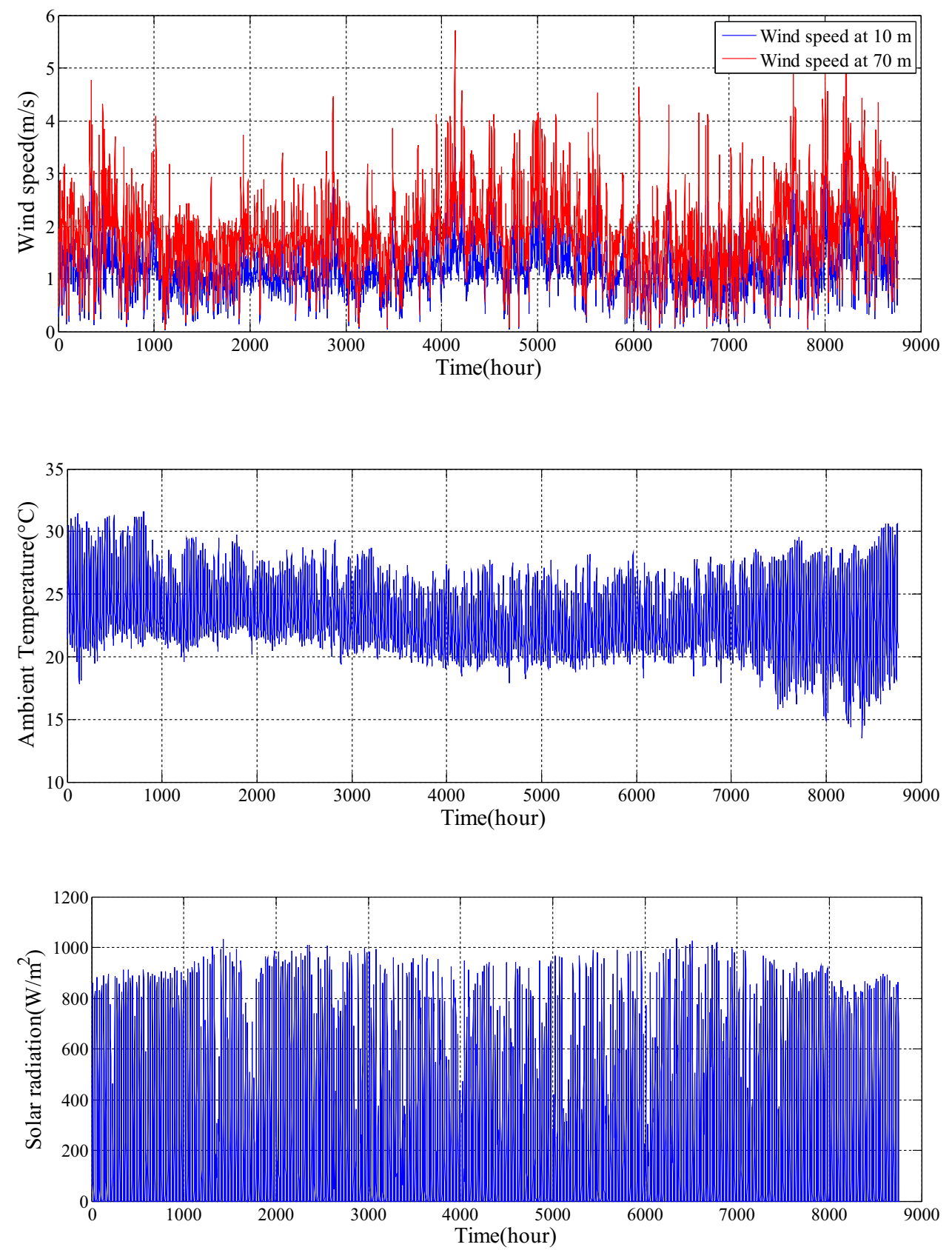

SN Applied Sciences 
- Case 3: The diesel generator will be used to supply the load when renewable energies and battery bank are not able to satisfy the load.

- Case 4: When the battery bank is fully charged, the excess power will be dumped by the dumping system.

\section{Optimization}

In this study we are going to minimize the LPSP, the NPC, the COE and the TGE and these are all known as the objectives functions. We are also going to consider four decision variables; which are: the rated power of the PV system $\left(P_{p v-r a t e d}\right)$, the number of wind turbines $\left(N_{w}\right)$, the days of autonomy of the battery bank $(A D)$ and the number of DG $\left(N_{d g}\right)$.

Among the four objective functions; LPSP, the NPC, the COE and the TGE, first priority is given to LPSP, second priority COE, third priority to NPC and the fourth to the TGE.

\subsection{Economic optimization model}

The NPC of the system is a very important element in the system design and it is taken over the project's lifetime. It includes the sum of the capital (C), operation \& maintenance $(\mathrm{OM})$, replacement $(\mathrm{R})$ costs for each component, plus the fuel cost for the diesel $\left(F C_{d g}\right)$ [9]. To improve the accuracy of the economic calculations there are important parameters since the rate of interest, the inflation rate and escalation rate. The NPC is calculated as follows [8]:

$N P C=C+O M+R+F C_{d g}$

The COE is another very important element in the system design and it is used as an indicator of economic profitability of the system. It is calculated using Eq. (8) [11]:

COE $=\frac{N P C}{\sum_{t=1}^{t=8760} P_{\text {load }}} \times C R F$

$P_{\text {load }}$ is the hourly power consumption. CRF is a ratio to calculate the present value of the system components for a given time period taking into consideration the interest rate [12]. It is calculated by:

$C R F=\frac{i(1+i)^{n}}{(1+i)^{n}-1}$

where $\mathrm{i}$ is the interest rate and $\mathrm{n}$ is the system lifetime, usually equal to the life of the PV system.

\subsection{Technical optimization model}

LPSP is defined as the reliability of the system and it represents the fraction of the load that is not met. If LPSP is 1 , then the load is never met while LPSP of zero implies that the load is fully met [12]. It is calculated using the Eq. (10):

$L P S P=\frac{\sum\left(P_{\text {load }}-P_{p v-\text { out }}-P_{\text {wind }}+P_{\text {bat-min }}+P_{\text {dg-out }}\right)}{\sum P_{\text {load }}}$

The renewable fraction (RF) is the fraction of the energy received by the load that is supplied by the renewable resources, it is the calculated using Eq. (11) [12]:

$R F=1-\frac{\sum_{t=1}^{8760} P_{d g-o u t}}{\sum_{t=1}^{8760} P_{R E}}$

where $P_{R E}$ indicates the sum of $\mathrm{PV}$ and wind powers.

\subsection{Greenhouse gases emission optimization model}

The emission of Greenhouse gases (GHG) by a hybrid renewable energy system is another important aspect to be considered when designing the system. The more GHG emitted from the system, the more harmful it will be to the environment and vice versa. The main component of the system responsible for this emission is the DG which mainly emits three gases [19]: $\mathrm{CO}_{2}, \mathrm{SO}_{2}$ and $\mathrm{NO}_{x}$.

To calculate the TGE of the system, we use the following expression:

$T G E=\sum_{t=1}^{8760}\left(\left(\alpha_{\mathrm{CO} 2}+\alpha_{\mathrm{SO2}}+\alpha_{\mathrm{NOx}}\right) \times P_{d g-\text { out }}\right.$

where TGE is the Total Greenhouse gases Emission, $\alpha_{\mathrm{CO} 2}$ $\alpha_{\mathrm{SO}_{2}}$ and $\alpha_{\mathrm{NO} x}$ are the emission factor of $\mathrm{CO}_{2}, \mathrm{SO}_{2}$ and $\mathrm{NO}_{x}$ respectively, $P_{d g-\text { out }}$ is the rated power of the DG. Table 5 gives the emission factors of $\mathrm{CO}_{2}, \mathrm{SO}_{2}$ and $\mathrm{NO}_{x}$ respectively.

\section{Particle swarm optimization algorithm}

PSO is one of the famous optimization techniques. It was first developed by Kennedy and Eberhart in 1995 [9]. It was founded based on the movement and behavior of birds and fish [20]. Generally, there are three main steps in the PSO algorithm stated as follows [12]:

- Evaluating the fitness of each particle using the objective functions

- Update individual and global best fitness and position

- Update velocity and position of each particle

Table 5 Emission factors

\begin{tabular}{llll}
\hline & $\mathrm{CO}_{2}$ & $\mathrm{SO}_{2}$ & $\mathrm{NO}_{x}$ \\
\hline Emission rate $(\mathrm{g} / \mathrm{kWh})$ & 697 & 0.5 & 0.22 \\
\hline
\end{tabular}


The best fitness value achieved by each particle is remembered by the particle during the algorithm operation. The particle having the best fitness value compared to other particles is equally calculated and updated during iterations [12]. This procedure is repeated till the stopping criteria are reached.

The velocity and the position of the particles are continuously updated as follows:

$v_{i}(t+1)=w v_{i}(t)+c_{1} r_{1}\left(P_{\text {besti }}-x_{i}(t)\right)+c_{2} r_{2}\left(G_{\text {besti }}-x_{i}(t)\right)$

$x_{i}(t+1)=x_{i}(t)+v_{i}(t+1)$

$w=w_{\text {min }}+\left(w_{\text {max }}-w_{\text {min }}\right) \times \frac{t}{\max _{\text {iter }}}$

where $r_{1}$ and $r_{2}$ are random real numbers drawn from $[0,1]$, $c_{1}$ and $c_{2}$ are the cognitive and social parameters respectively; pulling the particles towards $P_{\text {besti }}$ and $G_{\text {besti }}$ which are the personal or individual best and global best of each particle respectively. $w$ is the inertia weight $w_{\max } a n d w_{\min }$ are the initial and final inertia weights and $\max _{\text {iter }}$ is the maximum number of iterations.

This technique has evolved over time and in this study we are going to use the improved or constricted particle swarm optimization technique [20]. The constriction coefficient $\chi$ helps to ameliorate the convergence of the system [11]. With the introduction of the constriction coefficient, the velocity equation becomes:

$v_{i}(t+1)=\chi v_{i}(t)+c_{1} r_{1}\left(P_{\text {besti }}-x_{i}(t)\right)+c_{2} r_{2}\left(G_{\text {besti }}-x_{i}(t)\right)$

$c_{1}=\chi \cdot \varphi_{1}$

$c_{2}=\chi \cdot \varphi_{2}$

$\chi=\frac{2}{\left|\varphi-2+\operatorname{sqrt}\left(\varphi^{2}-4 \times \varphi\right)\right|}$

where $\varphi$ is the contraction coefficient and it is given by:

$\varphi=\varphi_{1}+\varphi_{2}$

With $\varphi_{1}=\varphi_{2}=2.05$

The steps of the PSO algorithm applied in this work are shown in Fig. 6.

Table 6 gives the constraints parameters of the various components of the system.

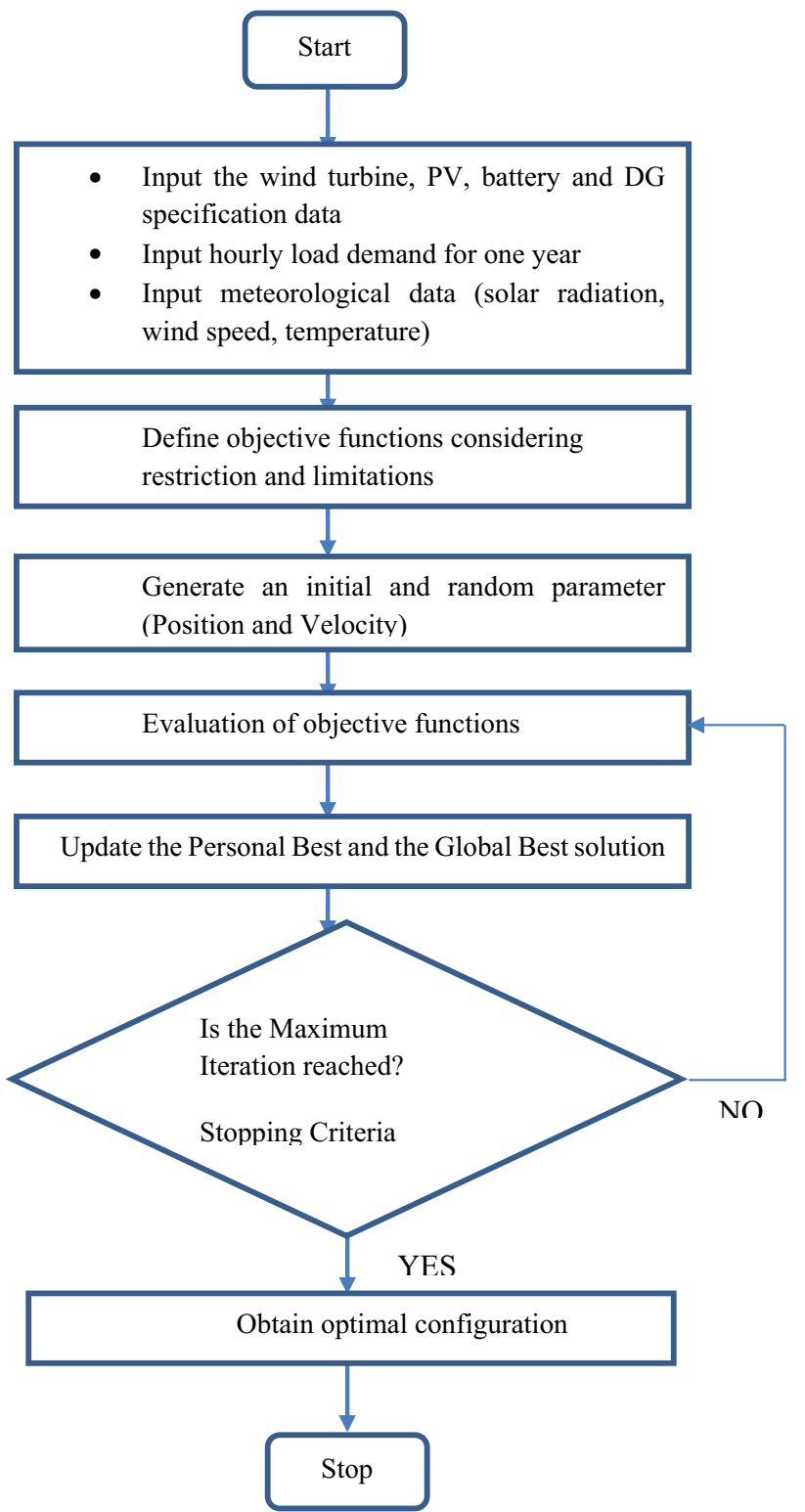

Fig. 6 Flowchart of the PSO algorithm

Table 6 Constraints parameters

\begin{tabular}{lll}
\hline & Minimum value & Maximum value \\
\hline$P_{p v-\text { rated }}$ & $11 \mathrm{~kW}$ & $18 \mathrm{~kW}$ \\
$N_{w}$ & 0 & 5 turbines \\
$A D$ & 0 & 3 days \\
$N_{d g}$ & 0 & 3 generators \\
\hline
\end{tabular}

\section{Results and discussion}

In this section, the optimal design and sizing of a standalone HRES for the Community Multimedia center 
in MAKENENE, Cameroon using PSO technique is presented. The system consists of wind turbines, PV, battery bank and DG as power back up as illustrated in Fig. 1. MATLAB (2012b) was used to implement this work. For the PSO technique, the population size and the maximum number of iteration were taken as 50 and 100 respectively. We assume the inflation and interest rate used are equal to $3.25 \%$.

In this study, various scenarios were considered and are presented as follows:

- Scenario 1: Hybrid system with PV, WT, Battery \& DG

- Scenario 2: Hybrid system with PV, Battery \&WT

- Scenario 3: Hybrid system with PV, Battery \& DG

- Scenario 4: Hybrid system with PV \& Battery

- Scenario 5: Hybrid system with Battery \& DG

- Scenario 6: Hybrid system with PV \& DG

- Scenario 7: System with DG only

The optimal results for the PSO algorithm for the various scenarios are presented in Table 7.

\subsection{Scenario 1 (photovoltaic, wind, battery and diesel generator)}

In this scenario, the hybrid system consists of PV, Wind, Battery and DG. From Table 7, we notice that the LPSP, the COE, the NPC and Emission are $0.004 \%, 0.140 \$ / \mathrm{kWh}$, $41,259.3 \$$ and $2.9 \mathrm{~kg} /$ year respectively. The rated PV power is $13 \mathrm{~kW}$ corresponding to $50 \mathrm{PV}$ panels, the number of wind turbines is 1, the days of autonomy is 3 and the number of diesel generator is 1 .

\subsection{Scenario 2 (photovoltaic, battery and wind)}

For this scenario, the system is made up of PV, Wind \& Battery. Table 7 shows that the LPSP, the COE, the NPC and Emission are $0.05 \%, 0.130 \$ / \mathrm{kWh}, 38,382.7 \$$ and $0 \mathrm{~kg} / \mathrm{year}$ respectively. The Emission here is 0 because we assumed that the system which is mainly made of renewable resources does not emit when it is operating. The rated PV power is $15 \mathrm{~kW}$ corresponding to $57 \mathrm{PV}$ panels, the number of wind turbines is 1 , the days of autonomy is 2 .

\subsection{Scenario 3 (photovoltaic, battery and diesel generator)}

Here the system is made of PV, Battery and DG. The LPSP, the COE, the NPC and Emission are $0.003 \%, 0.132 \$ / \mathrm{kWh}$, $38,817.7 \$$ and $2.2 \mathrm{~kg} /$ year respectively. The rated PV power is $14 \mathrm{~kW}$ corresponding to $54 \mathrm{PV}$ panels, the days of autonomy is 2 and the number of diesel generator is 1 .

We notice that Scenario 1 and Scenario 3 are having the same number of diesel generator but there is a difference in the Emission of GHG because in Scenario 1, the diesel generator is highly solicited that is has a higher number of operating hours compared to Scenario 3 (Fig. 7).

The hourly power output from the PV, Battery and DG for Scenario 3 are presented in Figs. 8, 9 and 10 respectively. Figure 7 presents a pie chart showing the percentages of power contribution of each component of the

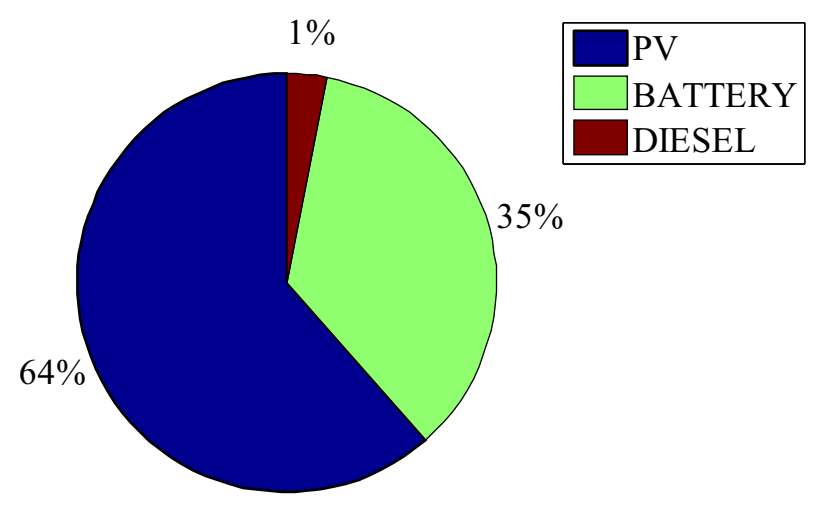

Fig. 7 Percentage of energy supplied by PV, battery and DG in Scenario 3

Table 7 Optimal Solutions for the various Scenarios

\begin{tabular}{|c|c|c|c|c|c|c|c|c|c|}
\hline Scenarios & $P_{p v-\text { rated }}(\mathrm{kW})$ & $N_{w}$ & $A D$ & $N_{d g}$ & LPSP (\%) & $\operatorname{COE}(\$ / k W h)$ & NPC (\$) & Emission (kg/year) & $\begin{array}{l}\text { Renew- } \\
\text { able } \\
\text { factor }\end{array}$ \\
\hline Scenario 1 & 13 & 1 & 3 & 1 & 0.004 & 0.140 & $41,259.3$ & 2.9 & 0.996 \\
\hline Scenario 2 & 15 & 1 & 2 & - & 0.05 & 0.130 & $38,382.7$ & 0 & 1 \\
\hline Scenario 3 & 14 & - & 2 & 1 & 0.003 & 0.132 & $38,817.7$ & 2.2 & 0.99 \\
\hline Scenario 4 & 14 & - & 2 & - & 0.05 & 0.108 & 31,752 & 0 & 1 \\
\hline Scenario 5 & - & - & 2 & 1 & 0.003 & 0.816 & $240,906.7$ & $22,489.7$ & 0 \\
\hline Scenario 6 & 14 & - & - & 2 & 0 & 2.008 & $592,347.2$ & $36,501.2$ & 0.4 \\
\hline Scenario 7 & - & - & - & 2 & 0 & 2.608 & $769,608.4$ & $44,406.5$ & 0 \\
\hline
\end{tabular}


Fig. 8 PV hourly output power for scenario 3
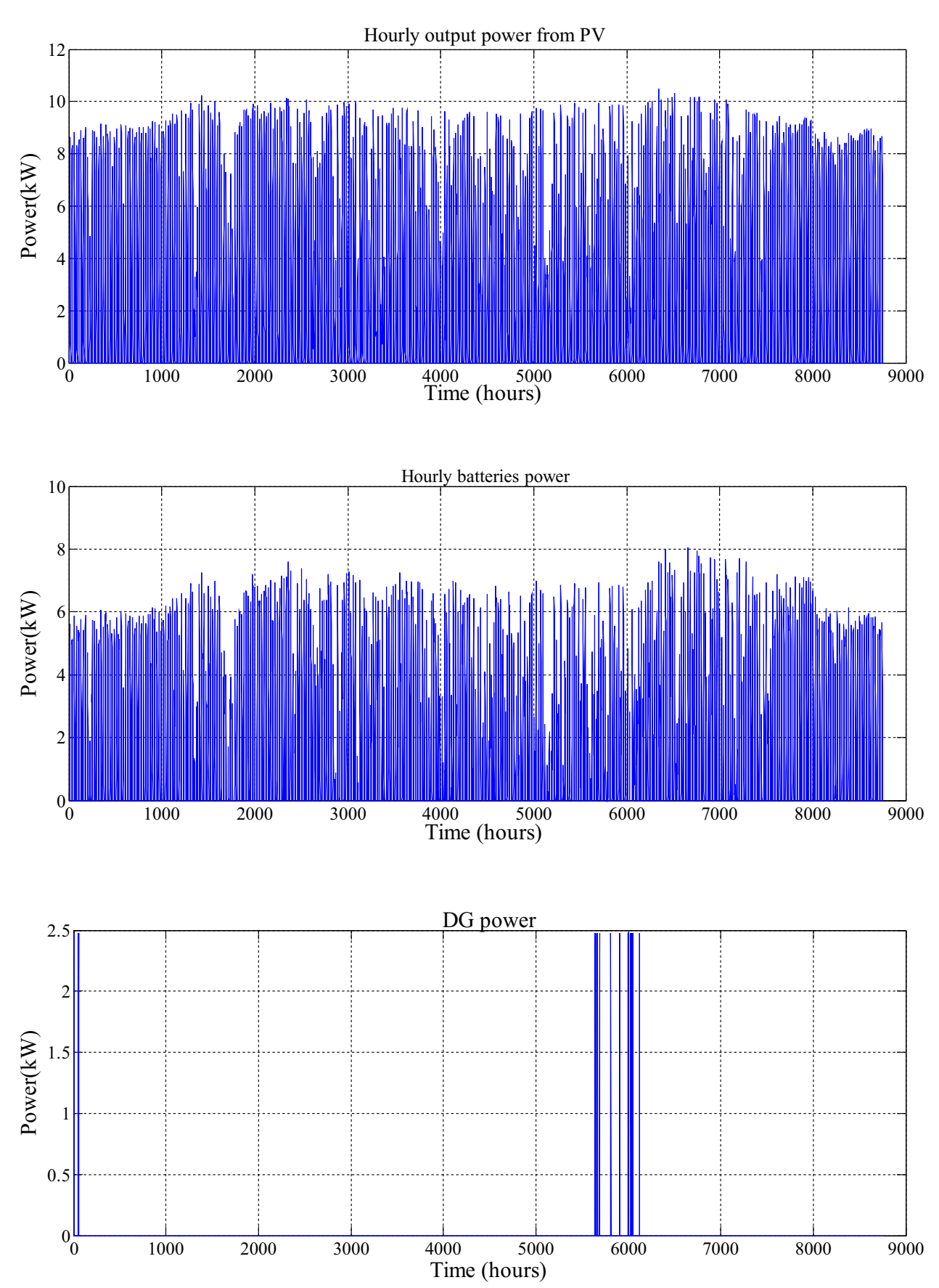

Fig. 9 Battery hourly power for scenario 3

Fig. 10 Hourly DG power output for scenario 3 system in Scenario 3 and it is clear that is most of the power comes from PV and Battery.

\subsection{Scenario 4 (photovoltaic and battery)}

For this configuration, the LPSP, the COE, the NPC and Emission are $0.05 \%, 0.108 \$ / \mathrm{kWh}, 31,752 \$$ and $0 \mathrm{~kg} /$ year respectively. The rated PV power is $14 \mathrm{~kW}$ corresponding to 54 PV panels, the days of autonomy is 2 . Similarly to Scenario 2, this Scenario is also having a null Emission.
Compared to other Scenarios, Scenario 4 has the lowest COE and NPC but the LPSP is highest just like in Scenario 2.

\subsection{Scenario 5 (diesel generator and battery)}

The solutions from Table 7 shows that for this configuration, the LPSP, the COE, the NPC and Emission are $0.003 \%$, $0.816 \$ / \mathrm{kWh}, 240,906.7 \$$ and $22,489.7 \mathrm{~kg} /$ year respectively. The days of autonomy is 2 and the number of diesel generator is 1 . Similarly to the Scenario 1 and Scenario 3 , Scenario 5 is also having 1 diesel generator but the 
Emission is higher here indicating that it has a higher number of operating hours. The NPC is also higher compared to Scenario 1-4, this indicates that the operating and replacement costs are higher in the course of the project's lifetime.

\subsection{Scenario 6 (photovoltaic and diesel generator)}

The solutions from Table 7 shows that for this configuration, the LPSP, the COE, the NPC and Emission are $0.0 \%$, $2.008 \$ / \mathrm{kWh}, 592,347.2 \$$ and $36,501.2 \mathrm{~kg} /$ year respectively. The rated PV power is $14 \mathrm{~kW}$ corresponding to 54 $\mathrm{PV}$ panels and the number of diesel generator is 2 . For this scenario, we have 2 diesel generators as opposed to one in Scenario 5; this is because there is no storage for the energy thus increasing the number of diesel generators when the PV component of the system cannot satisfy the load. Obviously, the COE, the NPC and Emission are higher though the load is entirely satisfied.

\subsection{Scenario 7 (diesel generator only)}

Here the system is mainly made of diesel generators. The solutions from Table 7 shows that for this configuration, the LPSP, the COE, the NPC and Emission are $0.0 \%, 2.608$
$\$ / \mathrm{kWh}, 769,608.4 \$$ and $44,406.5 \mathrm{~kg} /$ year respectively. The number of diesel generators here is 2 . Though the load is entirely satisfied for this configuration, the COE, the NPC and the Emission are the highest of all the scenarios.

Figures 11 and 12 present the COE convergence curves for the different scenarios of this study. Apart from Scenario 2, all the Scenarios present curves which converge in less than 10 iterations indicating the good performance of the PSO algorithm in this study.

\section{Conclusion}

In this paper, the optimal sizing of a standalone hybrid renewable energy system for a Community Multimedia center in MAKENENE, regarding the technical, economic and environmental aspects using PSO algorithm is presented. Seven Scenarios were considered for this study. In Scenarios 6 \&7, the load is completely satisfied but the systems have the highest COE, NPC and TGE thus being less economic and more harmful to the environment. Scenarios 2 and 4 has the lowest COE, NPC and TGE but the load is not completely satisfied with $0.05 \%$ of LPSP which is the highest of all the Scenarios. For Scenarios 1 and 3, the LPSP is $0.003 \%$ so a very negligible fraction of the load
Fig. 11 COE convergence for scenarios 1-4

Fig. 12 COE convergence for scenarios $5-7$
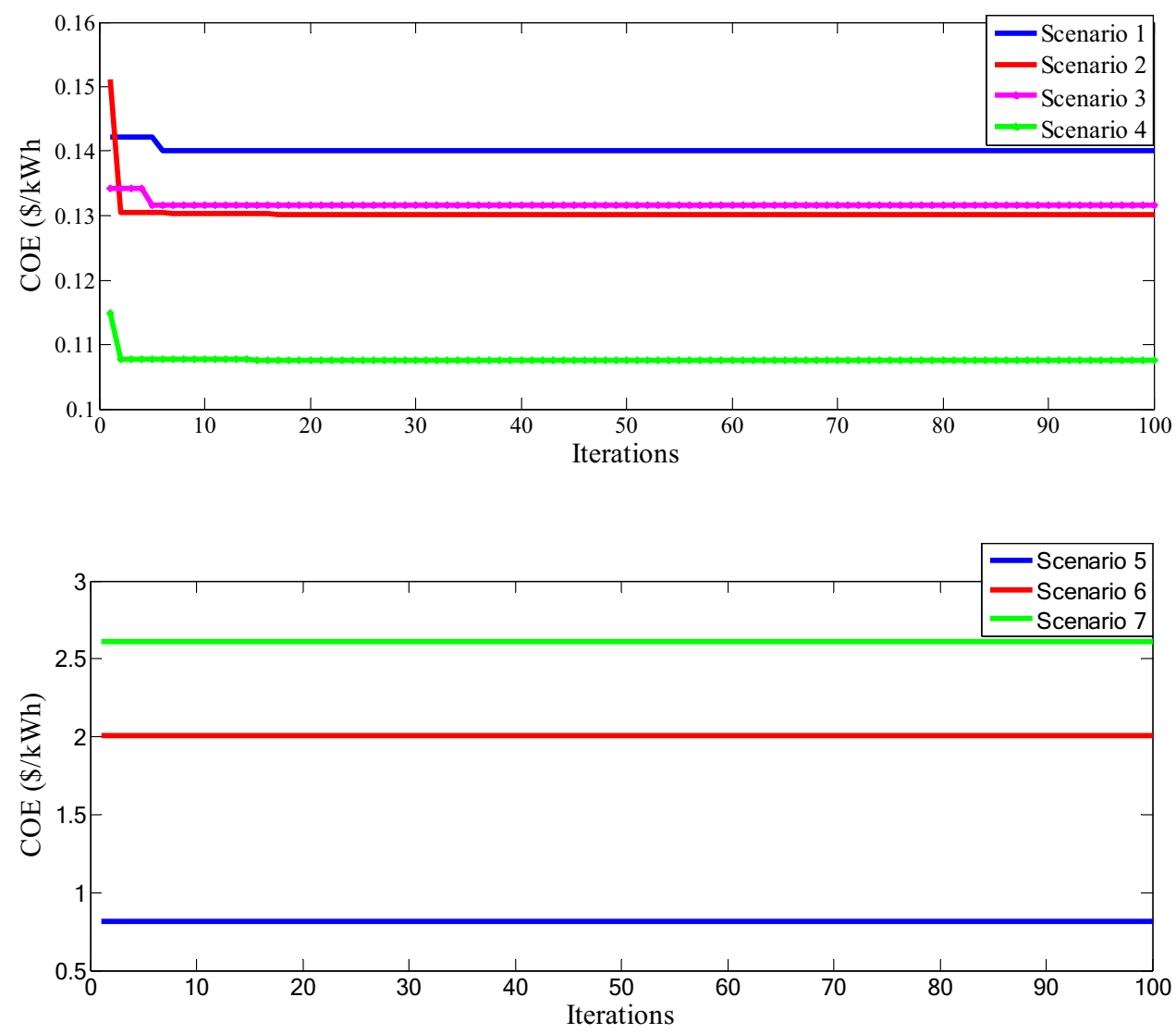
is not satisfied and also the COE $(0.140 \$ / \mathrm{kWh}$ and $0.132 \$ /$ kWh respectively) are lower but the system in Scenario 1 emits much GHG than that in Scenario 3. This shows that Scenario 3 is the only scenario where the load is almost completely satisfied, the cost is relatively low and the environment is less hurt. It can therefore be concluded that, the system in Scenario 3 is the best for the Community Multimedia center.

The outcomes of this study can serve as a guide for policy makers and investor for investment in renewable energy systems in Community Multimedia center in Cameroon as a whole. The best Scenario of this study is recommended because it is environmentally friendly due to the less TGE. In this work, only one optimization technique is used and it was not possible to get actual measured ground resource data recommended to achieve more realistic results of the viabilities of the various Scenarios. Equally, more government implication through the establishment of conducive policies, regulations, incentives and funding mechanisms necessary for the promotion of the country's renewable energy sector is recommended.

Future work would include actual ground resource data to achieve more realistic results. Also, we are going to use other optimization techniques and will make a comparative study with the one being used here. We are equally going to include other renewable energy resources like small hydroelectricity, biomass and increase the number of Scenarios.

\section{Compliance with ethical standards}

Conflict of interest The authors declare that they have no conflict of interest.

Open Access This article is licensed under a Creative Commons Attribution 4.0 International License, which permits use, sharing, adaptation, distribution and reproduction in any medium or format, as long as you give appropriate credit to the original author(s) and the source, provide a link to the Creative Commons licence, and indicate if changes were made. The images or other third party material in this article are included in the article's Creative Commons licence, unless indicated otherwise in a credit line to the material. If material is not included in the article's Creative Commons licence and your intended use is not permitted by statutory regulation or exceeds the permitted use, you will need to obtain permission directly from the copyright holder. To view a copy of this licence, visit http://creativecommons .org/licenses/by/4.0/.

\section{Reference}

1. Livshitz II, Lontsikh PA, Kunakov EP (2019) Application of a hybrid method for key energy facilities safety assessment. EAI Endorsed Trans Energy Web. https://doi.org/10.4108/eai.13-72018.156386
2. Khare V, Nema S, Baredar $P$ (2016) Solar wind hybrid renewable energy system: A review. Renew Sustain Energy Rev 58:23-33. https://doi.org/10.1016/j.rser.2015.12.223

3. Baek S, Park E, Kim M-G, Kwon SJ, Kim KJ, Pobil JY, OAP del, (2016) Optimal renewable power generation systems for bus an metropolitan city in south Korea. Renew Energy 88:517-525. https://doi.org/10.1016/j.renene.2015.11.058

4. Singh A, Baredar P, Gupta B (2015) Computational simulation and amp; optimization of a solar, fuel cell and biomass hybrid energy system using \{HOMER\} pro software. Procedia Eng 127:743-750. https://doi.org/10.1016/j.proeng.2015.11.408

5. Salisu S, Mustafa MW, Mohammed OO, Mustapha M (2019) Techno-economic feasibility analysis of an offgrid hybrid energy system for rural electrification in Nigeria. Int J Renew Energy Res 9(11):1-10

6. Pemndje J, llincab A, Tchinda R, Tene Fonganga TR (2016) Impact of using renewable energy on the cost of electricity and environment in Northern Cameroon. J Renew Energy Environ 3(4):34-43

7. Reza VB, Mazyar GN, Iraj A (2018) Optimally sized design of a wind/photovoltaic/fuel cell off-grid hybrid energy system by modified-grey wolf optimization algorithm. Energy Environ. https://doi.org/10.1063/1.4950945

8. Kharrich M, Mohammed O, Akherraz M (2020) Design of hybrid microgrid PV/wind/diesel/battery system: case study for Rabat and Baghdad. EAI Endorsed Trans Energy Web. https://doi. org/10.4108/eai.13-7-2018.162692

9. Mohamed OH, Benbouzid YA (2019) Particle swarm optimization of a hybrid wind/tidal/pv/battery energy system. Application to a remote area in Bretagne, France. Energy Procedia 162:87-96. https://doi.org/10.1016/j.egypro.2019.04.010

10. Maleki A, Pourfayaz MA, Fathollah R (2017) Optimal operation of a grid-connected hybrid renewable energy system for residential applications. Sustainability. https://doi.org/10.3390/su908 1314

11. Charfi S, Atieh A, Chaabenea M (2018) Optimal sizing of a hybrid solar energy system using particle swarm optimization algorithm based on cost and pollution criteria. Environ Prog Sustain Energy. https://doi.org/10.1002/ep.13055

12. Borhanazad H, Mekhilef S, Ganapathy VG, Mirtheri M, ModiriDelshad A (2014) Optimization of micro-grid system using MOPSO. Renew Energy 117:295-306. https://doi.org/10.1016/j. renene.2014.05.006

13. Yusra S, Hermaga et SZ, Erwin Y (2015) Optimal cost valuation for renewable power plant using PSO in rural area. Int J Electr Eng Inform 7(14):1-17. https://doi.org/10.15676/ijeei.2015.7.4.6

14. Flora F, Donatien N, Tchinda R, Hamandjoda O (2019) Impact of sustainable electricity for Cameroonian population through energy efficiency and renewable energies. J Power Energy Eng 7:11-51. https://doi.org/10.4236/jpee.2019.79002

15. AEEP-Cameroun (2013) Apercu du marche electrique au Cameroun

16. USAID (2019) Off-grid solar market assessment - Cameroon. Power Africa off-grid project

17. Abdel-Karim D, Mahmoud SI (2012) Design of isolated hybrid systems minimizing costs and pollutant emissions. Renew Energy 144:215-224. https://doi.org/10.1016/j.renen e.2012.01.011

18. Ramli M, Bouchekara $H$, Alghamdi A (2018) Optimal sizing of $\{\mathrm{PV}\} /$ wind/diesel hybrid microgrid system using multi-objective self-adaptive differential evolution algorithm. Renew Energy 1121:400-411

19. Kumar VVSN, Murty A (2020) Multi-objective energy management in microgrids with hybrid energy sources and battery energy storage systems. Prot Control Mod Power Syst. https:// doi.org/10.1186/s41601-019-0147-z 
20. Maleki A, Hafeznia H, Rosen M, Pourfayaz F (2017) Optimization of a grid-connected hybrid solar-wind-hydrogen CHP system for residential applications by efficient metaheuristic approaches. Appl Therm Eng 1123:1263-1277. https://doi.org/10.1016/j. applthermaleng.2017.05.100
Publisher's Note Springer Nature remains neutral with regard to jurisdictional claims in published maps and institutional affiliations.

\section{SN Applied Sciences}

A SPRINGER NATURE journal 